\title{
¿Black Carbon Increases Frequency of Extreme ENSO Events
}

\author{
SiJiA Lou, ${ }^{\mathrm{a}}$ YANG YANG, ${ }^{\mathrm{b}}$ HAILONG WANG,${ }^{\mathrm{a}}$ JiAn Lu, ${ }^{\mathrm{a}}$ STEVEN J. SMITH, ${ }^{\mathrm{c}}$ FuKAI LiU, ${ }^{\mathrm{d}}$ AND \\ PHILIP J. RASCH ${ }^{\mathrm{a}}$ \\ a Atmospheric Sciences and Global Change Division, Pacific Northwest National Laboratory, Richland, Washington \\ ${ }^{\mathrm{b}}$ Jiangsu Key Laboratory of Atmospheric Environment Monitoring and Pollution Control, Jiangsu Collaborative Innovation \\ Center of Atmospheric Environment and Equipment Technology, School of Environmental Science and Engineering, \\ Nanjing University of Information Science and Technology, Nanjing, China \\ ${ }^{\mathrm{c}}$ Joint Global Change Research Institute, Pacific Northwest National Laboratory, College Park, Maryland \\ d Physical Oceanography Laboratory/CIMST, Ocean University of China, Qingdao National Laboratory for \\ Marine Science and Technology, Qingdao, China
}

(Manuscript received 19 July 2019, in final form 10 September 2019)

\begin{abstract}
El Niño-Southern Oscillation (ENSO) is the leading mode of Earth's climate variability at interannual time scales with profound ecological and societal impacts, and it is projected to intensify in many climate models as the climate warms under the forcing of increasing $\mathrm{CO}_{2}$ concentration. Since the preindustrial era, black carbon (BC) emissions have substantially increased in the Northern Hemisphere. But how BC aerosol forcing may influence the occurrence of the extreme ENSO events has rarely been investigated. In this study, using simulations of a global climate model, we show that increases in BC emissions from both the midlatitudes and Arctic weaken latitudinal temperature gradients and northward heat transport, decrease tropical energy divergence, and increase sea surface temperature over the tropical oceans, with a surprising consequential increase in the frequency of extreme ENSO events. A corollary of this study is that reducing $\mathrm{BC}$ emissions might serve to mitigate the possible increasing frequency of extreme ENSO events under greenhouse warming, if the modeling result can be translated into the climate in reality.
\end{abstract}

\section{Introduction}

Black carbon (BC) aerosols have multiple impacts on the atmosphere by 1) absorbing energy within the atmospheric column (Boucher et al. 2013; Yang et al. 2019), 2) affecting cloud microphysical and dynamical processes, and 3) reducing surface albedo through deposition on snow and ice (Jacobson 2006; Ramanathan and Carmichael 2008; Qian et al. 2015). At the global scale, present-day BC exerts a relative weak effective radiative forcing of $0.082(0.041-0.291) \mathrm{W} \mathrm{m}^{-2}$ at the top of the atmosphere (TOA) as implied in Stjern et al. (2017), but regionally it can exert significant climatic impacts through amplifying warming in the Arctic and Tibetan Plateau (Flanner et al. 2007; He et al. 2014; AMAP 2015) and dynamical impacts through changing monsoon circulation (Lou et al. 2019) and

D Denotes content that is immediately available upon publication as open access.

Corresponding author: Yang Yang, yang.yang@nuist.edu.cn
El Niño-Southern Oscillation (ENSO), the latter being the subject of focus of this study.

ENSO is the leading mode of variability of the coupled climate system at interannual time scales (Ropelewski and Halpert 1987). It features anomalous warm (El Niño) and cold (La Niña) conditions every 2-7 years in the equatorial Pacific, affecting ecosystems, agriculture, and severe weather events globally (Bove et al. 1998; McPhaden et al. 2006). Some recent studies have found that the frequency of extreme ENSO events may increase in response to greenhouse warming (e.g., Cai et al. 2014, 2015), while other studies showed otherwise (e.g., Kohyama et al. 2018). It has also been reported that aerosols and their precursor gases could influence ENSO variability, but most previous studies have focused on natural aerosols. Based on model simulations, some studies found that tropical volcanic eruptions injecting $\mathrm{SO}_{2}$ (precursor of sulfate aerosol) into the stratosphere influenced ENSO variability (McGregor and Timmermann 2011; Ohba et al. 2013; Maher et al. 2015; Stevenson et al. 2016). Xu et al. (2016) showed that variations in oceanic dimethyl sulfide emissions (another 
natural precursor of sulfate aerosol) due to strong wind variability during La Niña events in turn increased the frequency of La Niña events. In a simulation with interactive natural dust aerosol capability, Rotstayn et al. (2011) found that their model can better reproduce ENSO-related precipitation variability through changing radiative balance and therefore surface evaporation over the southwest Pacific Ocean. Yang et al. (2016a,b) proposed a positive feedback between natural sea salt emission and ENSO, in which changes in sea salt emissions enhance ENSO variability.

Global total BC emissions from anthropogenic sources had an eightfold increase in 2010 relative to 1850 (about sixfold in the Northern Hemisphere midlatitudes and 32-fold in the Arctic) (Hoesly et al. 2018). As a short-lived climate forcing agent, light-absorbing BC warms the atmosphere, but the $\mathrm{BC}$ forcing is highly variable in space and time due to the heterogeneity of $\mathrm{BC}$ emission sources, short lifetime, and complex interactions with the climate. How the anthropogenic BC may potentially influence ENSO frequency and magnitude has been left largely unexplored.

Here we investigate the impact of $\mathrm{BC}$ on the frequency of extreme ENSO events using a coupled global aerosolclimate model. The model, emissions, and numerical experiment are described in section 2 . In section 3, we analyze the impacts of the present-day global anthropogenic $\mathrm{BC}$ emissions. Because the largest preindustrial to present-day $\mathrm{BC}$ emission changes are in the Northern Hemisphere midlatitude region (hereafter, midlatitudes) and $\mathrm{BC}$ emissions may increase in the Arctic through increased human activities (e.g., international shipping), influences of BC emissions from both the Northern Hemisphere midlatitudes and the Arctic are examined in section 4. Section 5 evaluates the potential mechanisms of BC impacts on extreme ENSO frequency. Section 6 summarizes these results and conclusions.

\section{Methods}

To assess the influence of $\mathrm{BC}$ on the frequency of extreme ENSO events, we conduct a series of BC emissiondriven climate model sensitivity experiments, as further described in Yang et al. (2019) and Lou et al. (2019). We conduct simulations with the Community Earth System Model (CESM; Hurrell et al. 2013), version 1.2, in which $\mathrm{BC}$, along with other aerosol types, is represented using the 4-mode Modal Aerosol Module (MAM4; Liu et al. 2016) with the aging processes of primary carbonaceous aerosols included. The model considers BC impacts on climate through aerosol-radiation and aerosol-cloud interactions and BC snow-albedo effect on top of land and sea ice. Improved characterization of convective
TABLE 1. Simulations performed in this study. All other emissions and conditions are fixed at year 1850 levels to avoid other anthropogenic influences, except for BC.

\begin{tabular}{|c|c|}
\hline Simulations & Details \\
\hline PI & $\begin{array}{l}\text { Simulation for BC in preindustrial conditions. } \\
\text { Anthropogenic } \mathrm{BC} \text { emissions are at year } 1850 \text { levels. }\end{array}$ \\
\hline PD & $\begin{array}{l}\text { Simulation for BC in present-day conditions. } \\
\text { Anthropogenic BC emissions are fixed at year } \\
2010 \text { (average of 2008-12). }\end{array}$ \\
\hline MID7X & $\begin{array}{l}\text { Sensitivity simulation to quantify the ENSO re- } \\
\text { sponses to midlatitude BC emissions. As in PD, } \\
\text { except that year-2010-level anthropogenic BC } \\
\text { emissions over the midlatitudes }\left(28^{\circ}-60^{\circ} \mathrm{N}\right) \text { are } \\
\text { scaled by a factor of } 7 \text {. }\end{array}$ \\
\hline ARC150X & $\begin{array}{l}\text { Sensitivity simulation to quantify the ENSO responses } \\
\text { to Arctic BC emissions. As in PD, except that year- } \\
\text { 2010-level anthropogenic BC emissions over the } \\
\text { Arctic }\left(60^{\circ}-90^{\circ} \mathrm{N}\right) \text { are scaled by a factor of } 150 \text {. }\end{array}$ \\
\hline
\end{tabular}

transport and wet scavenging of aerosols is also included in the model (Wang et al. 2013). BC simulations in this model version have been fully evaluated in previous studies (Liu et al. 2016; Yang et al. 2017a, 2018).

First, two 100-yr basic simulations (Table 1) with anthropogenic BC emissions kept at year 2010 (PD) and 1850 (PI) levels were conducted to investigate the possible influence of present-day anthropogenic BC emissions on the frequency of ENSO events. However, the global surface air temperature responses to present-day anthropogenic $\mathrm{BC}$ emissions are weak in this model relative to the internal variability (Baker et al. 2015; Yang et al. 2019). To simulate a significant climate response signal, many studies scale BC emissions up by large factors (e.g., Sand et al. 2013, 2015; Stjern et al. 2017; Tang et al. 2018; Yang et al. 2019). In this study, we also explore the model response to larger forcing, by scaling up BC emissions following Sand et al. (2013). Two 100-yr sensitivity simulations are performed, including a simulation same as PD except that present-day anthropogenic $\mathrm{BC}$ emissions over the midlatitudes $\left(28^{\circ}-60^{\circ} \mathrm{N}\right)$ are scaled up by a factor of 7 (MID7X) and a simulation same as PD except that present-day anthropogenic BC emissions over the Arctic $\left(60^{\circ}-90^{\circ} \mathrm{N}\right)$ are scaled up by a factor of 150 (ARC150X). The scaling factor for BC emissions (7 for MID7X and 150 for ARC150X) follows Sand et al. (2013) to give detectable forced signals. The same scaling factors also offers an opportunity for a comparison of BC-induced climate change here to that in Sand et al. (2013), which has been assessed in Yang et al. (2019). All other emissions and conditions are fixed at year 1850 levels to exclude other anthropogenic influences. The last 80 years of all simulations are used for analysis, following a $20-y r$ model spinup. Note that the large scaling factors do not mean that 
$\mathrm{BC}$ emissions would be increased by these extreme large amounts in the real world, but are used to produce sufficient signal to qualitatively examine the ENSO responses to the midlatitude and Arctic BC emissions.

Anthropogenic BC emissions used in this study are from the Community Emissions Data System (CEDS, version 2017-05-18; Hoesly et al. 2018) dataset developed for phase 6 of the Coupled Model Intercomparison Project (CMIP6). The differences in anthropogenic BC emissions between PD and PI and between MID7X/ARC150X and PD simulations are shown in Fig. 1. PD has 6.80 $\mathrm{Tg} \mathrm{Cyr}^{-1}$ more global total anthropogenic BC emissions than PI, most of which are located in the North Hemisphere midlatitude regions, with only $1.0 \mathrm{Tg} \mathrm{Cyr}^{-1}$ increased emission occurring in the Southern Hemisphere based on the CEDS emission inventory. Compared to the emissions in PD, ARC150X includes an additional 12.63 $\mathrm{Tg} \mathrm{C} \mathrm{yr}^{-1} \mathrm{BC}$ emissions in the Arctic and MID7X has $20.74 \mathrm{Tg} \mathrm{C} \mathrm{yr}^{-1}$ more $\mathrm{BC}$ emissions in midlatitudes.

Previous studies have reported that CESM overestimated ENSO variability and intensity (Otto-Bliesner et al. 2016; Yang et al. 2016b; Golaz et al. 2019). We also found that CESM simulations tend to predict more extreme ENSO events compared to ERA-Interim (Fig. 2). We therefore examine conditions between PD and PI, as well as in the perturbed simulations relative to the CESM PD run, therefore, the analysis will be only focusing on the ENSO changes within the CESM system.

We also use sea surface temperature (SST) data from a 1400-yr CESM preindustrial control simulation (Kay et al. 2015) as a baseline to test the statistical significance of changes in the frequency of the extreme ENSO conditions in the perturbed simulations. To further examine the nature of the difference in Niño-3.4 frequency distribution, we first construct a preindustrial probability distribution function (PDF) for each 1-K interval of the monthly Niño-3.4 index using 1000 random samples of consecutive 960-month (80 yr) results from the 1400-yr CESM preindustrial simulation using a Monte Carlo method. Within each 1-K bin, if the difference is greater than the 95th percentile or less than the 5th percentile of the preindustrial PDF, the change in Niño-3.4 index distribution at that bin is deemed significant. This nonparametric method has previously been used to test the significance of probability change of daily surface temperature extremes (Xue et al. 2017), and makes no prior assumptions about the shape of the statistical distribution.

The Niño-3.4 index is used in this study to characterize the intensity of ENSO conditions and is computed as the monthly mean SST anomaly over the Niño-3.4 region $\left(5^{\circ} \mathrm{S}-5^{\circ} \mathrm{N}, 170^{\circ}-120^{\circ} \mathrm{W}\right)$ for each simulation individually. An El Niño (La Niña) event is defined when the 3-month running average of the Niño-3.4 index
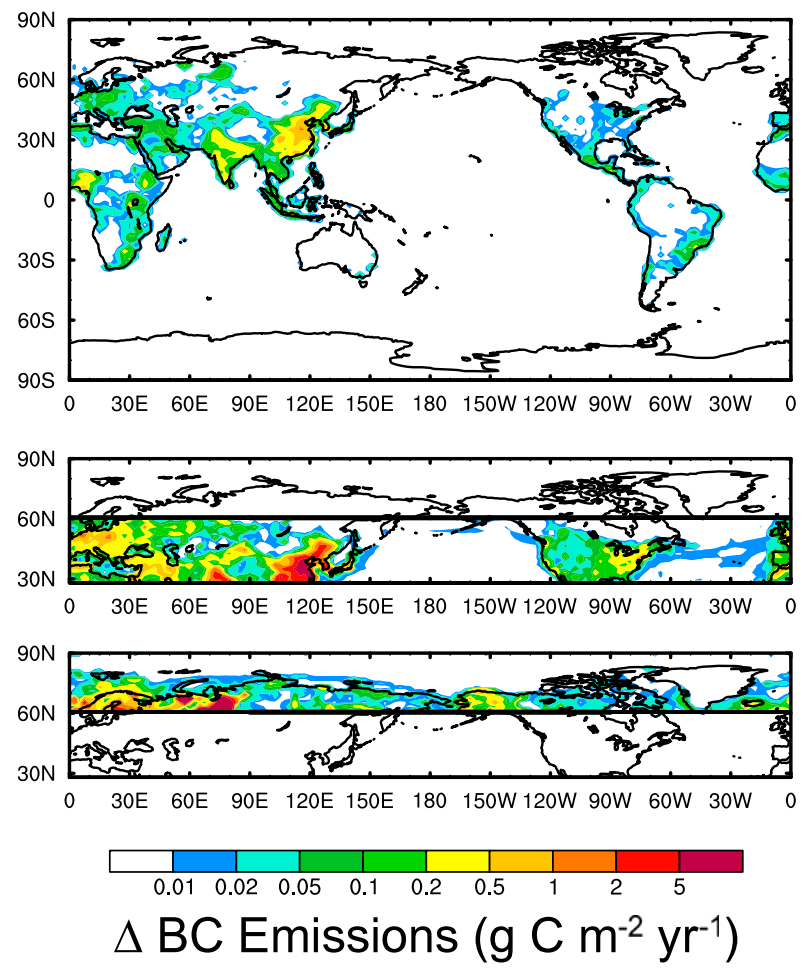

FIG. 1. Differences in annual mean anthropogenic black carbon (BC) emission $\left(\mathrm{g} \mathrm{C} \mathrm{m}^{-2} \mathrm{yr}^{-1}\right.$ ) (top) between PD and PI, (middle) between MID7X and PD, and (bottom) between ARC150X and PD simulations.

reaches or exceeds $0.5 \mathrm{~K}$ (is less than $-0.5 \mathrm{~K}$ ) for at least 5 months. The maximum (minimum) value of the 3-month running-average Niño-3.4 index during an El Niño (La Niña) event is the peak intensity of the event (Yu et al. 2019). In Yu et al. (2019), the extreme El Niño events are identified when their peak intensities higher than $2.5 \mathrm{~K}$. Since CESM overestimates ENSO intensity, in this study, we increase the threshold to be $3 \mathrm{~K}$ for the extreme El Niño events in CESM model, while negative peak anomalies lower than $-2 \mathrm{~K}$ are identified to be extreme $\mathrm{La}$ Niña events to account for the asymmetry between the warm and cold events as evidenced in Fig. 2. In addition, we also define the extreme El Niño or La Niña events based on the December-February (DJF) seasonal mean Niño-3.4 index [as done in Cai et al. $(2014,2015)]$, using the same respective thresholds. The main conclusions regarding the ENSO response do not differ qualitatively, no matter whether monthly or seasonal indices are used for the definition of the extreme ENSO events.

\section{Impacts of present-day BC on extreme ENSO frequency}

Figure 3 compares the standard deviation (STD) of monthly SST anomaly between PI and PD simulations. 

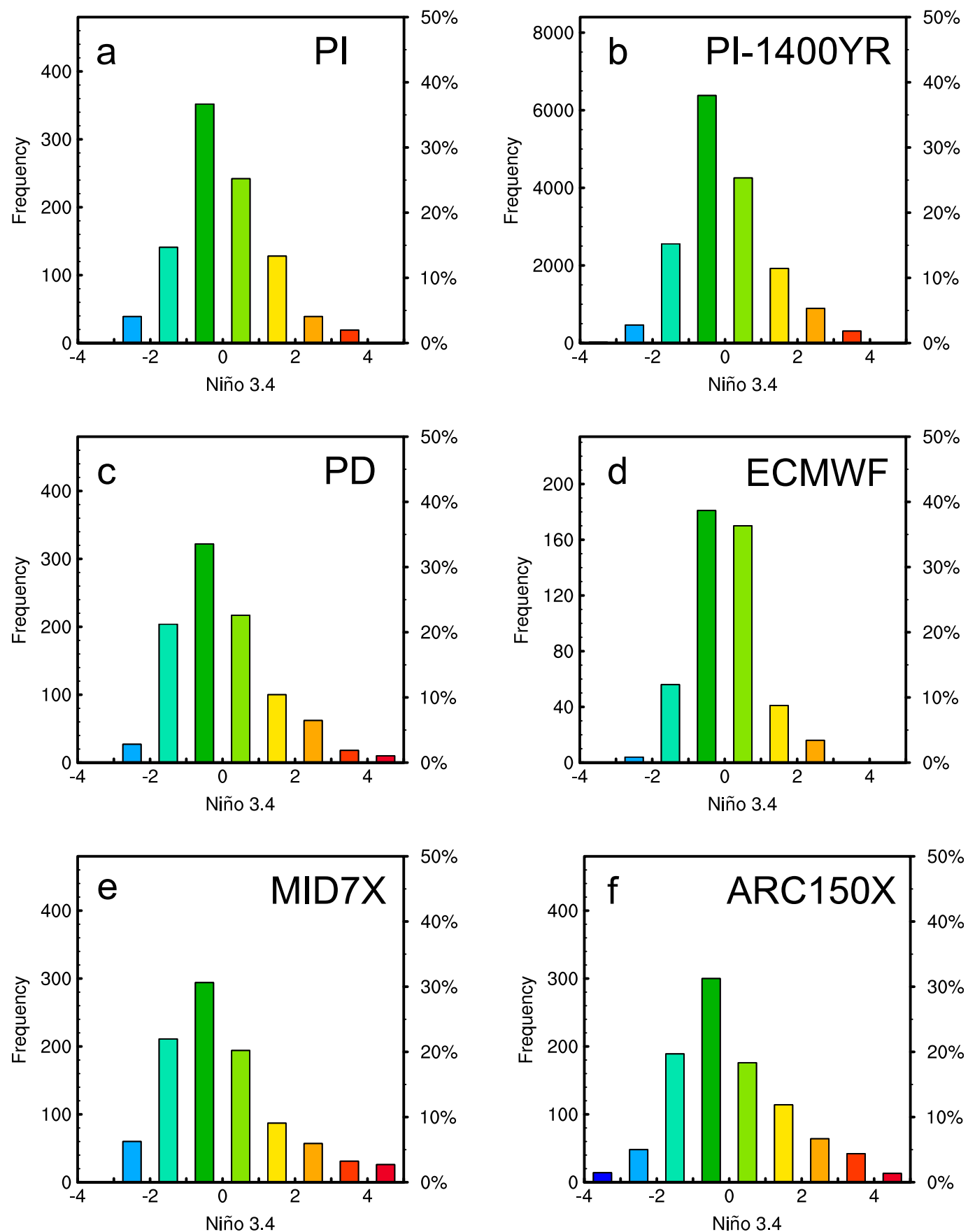

FIG. 2. Histograms of the monthly Niño-3.4 index from (a) PI, (c) PD, (e) MID7X, and (f) ARC150X simulations, as well as from (b) the 1400-yr CESM preindustrial simulation and (d) ERA-Interim for years 1979-2017.

With present-day global anthropogenic BC emission included, variability in the SST anomaly increases in the equatorial Pacific, with the largest STD over the equatorial eastern increased from $1.3-1.4 \mathrm{~K}$ in PI to more than $1.6 \mathrm{~K}$ in PD. The standard deviation of the Niño-3.4 index is 1.20 and $1.34 \mathrm{~K}$ in PI and $\mathrm{PD}$, respectively, indicating a wider distribution and an increase in the frequency of extreme ENSO amplitudes in PD compared to PI. However, we note that these are unlikely to be normal distributions based on the Shapiro-Wilks test $(p<1 \%)$. We, therefore, use nonparametric statistical tests, such KolmogorovSmirnov (Massey 1951), to evaluate our results as explained below. 

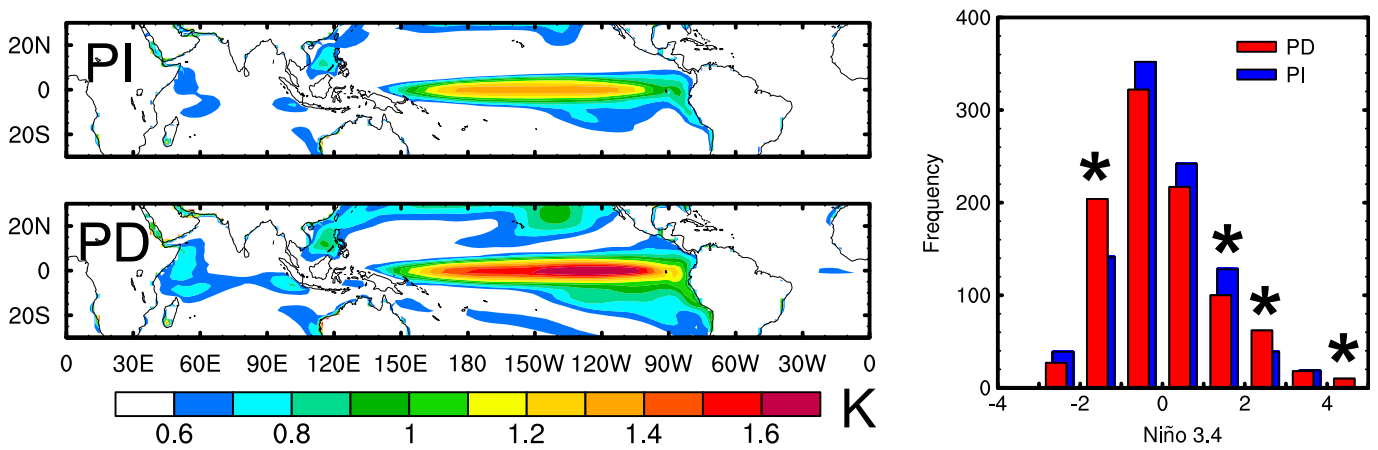

FIG. 3. (left) Standard deviation of monthly sea surface temperature anomaly (K) in (top) PI and (bottom) PD simulations and (right) histograms of the monthly Niño-3.4 index for PD (red bars) and PI simulation (blue bars). In total, 960 months for the last 80 years of each simulation are analyzed. Bars with an asterisk indicate statistically significant changes with respect to the upper and lower 5 th percentiles of a probability distribution function for each Niño-3.4 index bin derived from a 1400-yr CESM preindustrial simulation (see text).

Figure 3 also shows histograms of the monthly Niño3.4 index for the PD and PI simulations. The Niño-3.4 frequency distribution from PD differs from the PI distribution based on the Kolmogorov-Smirnov test $(p<$ $2.5 \%)$, suggesting that increases in present-day global anthropogenic $\mathrm{BC}$ emissions may be responsible for changes in the frequency of ENSO conditions. Based on a 1400-yr CESM simulation together with the Monte Carlo method illustrated in the methods section, we found that the frequencies of Niño-3.4 falling into PD intervals of 2 to 3,5 to 6 , and -1 to $-2 \mathrm{~K}$ are higher than PI with $95 \%$ confidence level. However, the changes in intervals of 3 to $4 \mathrm{~K}$ and -2 to $-3 \mathrm{~K}$ did not pass the test. The frequency of extreme El Niño, calculated based on the peak ENSO intensity, remains unchanged (4 events per 80 years) and the frequency of extreme La Niña even decreases (from 5 events to 3 events per 80 years) between PI and PD simulation. If the extreme ENSO events are calculated based on the DJF mean Niño-3.4 index, the frequency of extreme El Niño (La Niña) exhibits nonsignificant change: from 4 (4) to 3 (5) events per 80 years. This is consistent with an early study (Yang et al. 2019) that the sea surface temperature responses to present-day $\mathrm{BC}$ emissions at global scale are weak compared to internal variability. We, therefore, focus our analysis on simulations with scaled-up BC emission perturbations and examine the possible mechanisms behind the significant response therein.

\section{Impacts of midlatitude and Arctic BC on extreme ENSO frequency}

We first note that, despite the scale-up of the BC emissions, the resultant global and regional forcings are still similar in magnitude to other aerosol forcings. The direct radiative forcing in MID7X increases to $2.5 \mathrm{~W} \mathrm{~m}^{-2}$ averaged in midlatitudes of the Northern Hemisphere $\left(28^{\circ}-60^{\circ} \mathrm{N}\right)$ and the forcing in ARC150X increases to $4 \mathrm{~W} \mathrm{~m}^{-2}$ in the Arctic (Yang et al. 2019), these being similar in magnitude, for example, to the regional values of sulfate indirect forcing in this model (Yang et al. 2017b).

The standard deviation of the Niño-3.4 index increased from $1.20 \mathrm{~K}$ in PD to $1.56 \mathrm{~K}$ in MID7X and $1.58 \mathrm{~K}$ in ARC150X. The histograms of the monthly Niño-3.4 index from the MID7X and ARC150X simulations are compared with that from PD in Figs. $4 a$ and $4 b$, respectively. Note that the Niño-3.4 frequency distributions from MID7X and ARC150X are different from the PD distribution based on the Kolmogorov-Smirnov test $(p<2.5 \%)$. We find that increases in BC emissions from both the midlatitude and Arctic results in increased frequencies in the positive and negative tails of the monthly ENSO index. Changes in the frequency of ENSO conditions with Niño-3.4 index higher than $3 \mathrm{~K}$ or lower than $-2 \mathrm{~K}$ fall outside the $95 \%$ confidence range of the preindustrial statistical distribution for both MID7X and ARC150X compared to PD, with the extreme El Niño months increased from 28 in PD to 57 in MID7X and 55 in ARC150X and the extreme La Niña months increased from 27 months in PD to 60 months in MID7X and 62 months in ARC150X. It suggests that increases in BC emissions from both the midlatitudes and Arctic can increase the frequency of extreme El Niño and La Niña conditions, at least in the context of the CESM system.

In terms of DJF seasonal index-based definition of extreme ENSO events, the frequency of extreme El Niño (La Niña) increases from 4 (4) events in PD to 7 (8) events in MID7X per 80 years (Fig. 4c). Similarly, the frequency of extreme El Niño (La Niña) events is doubled, from 4 (4) in PD to 8 (8) in ARC150X (Fig. 4d). The changes of extreme ENSO events in both scaled-up 

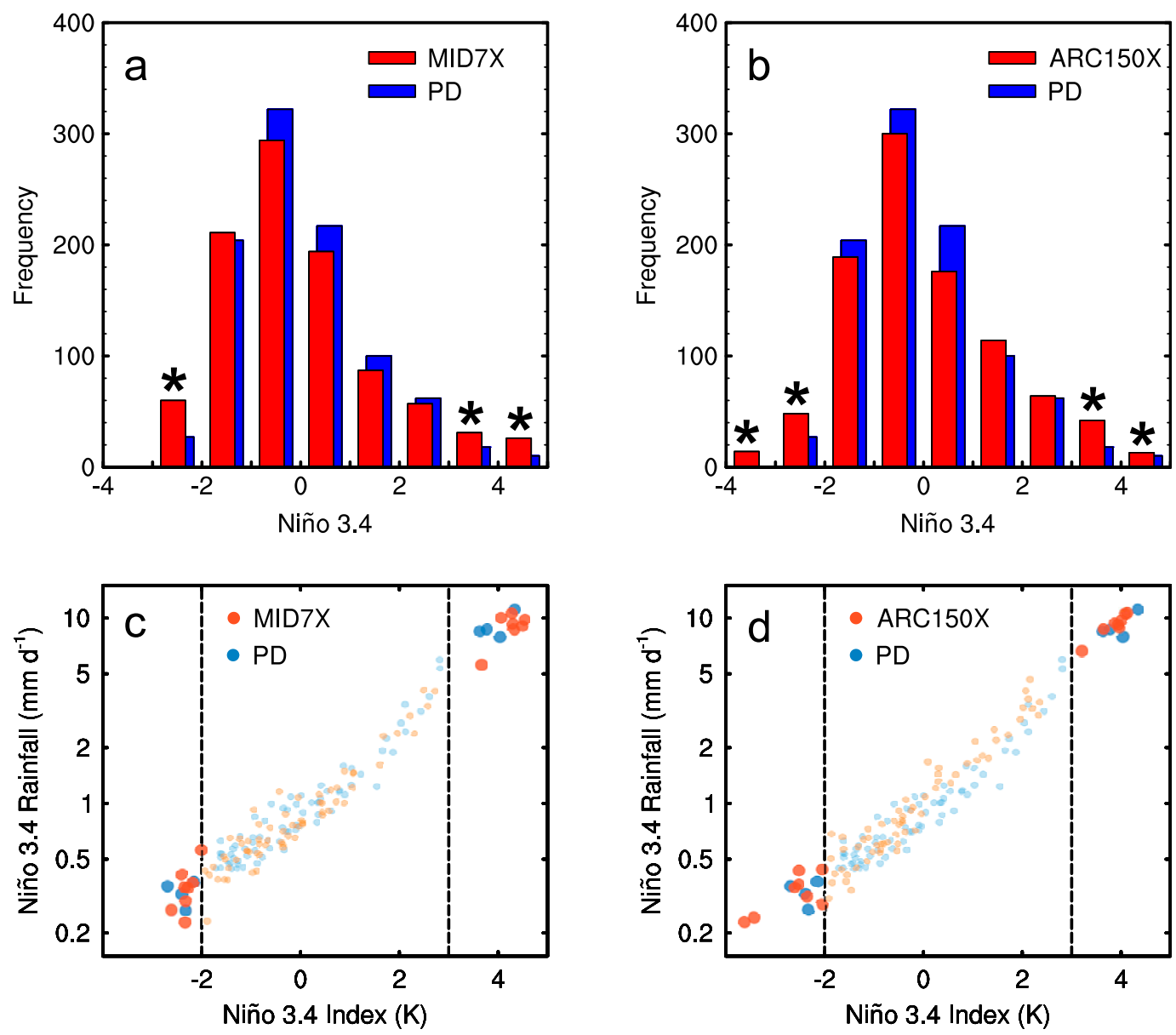

FIG. 4. (top) Histograms of the monthly Niño-3.4 index (K) for (a) MID7X and (b) ARC150X as compared to PD. (bottom) Relationships between DJF total rainfall $\left(\mathrm{mm} \mathrm{day}^{-1}\right)$ in the Niño-3.4 area and DJF Niño-3.4 index (K) in (c) MID7X and (d) ARC150X as compared to PD. In (c) and (d), the cases exceeding the extreme thresholds are denoted by more saturated color.

emissions pass the Monte Carlo test with 95\% confidence level. Accompanying the more frequent extreme El Niño events, the extreme precipitation events with seasonal rainfall higher than $5 \mathrm{~mm} \mathrm{day}^{-1}$ also become more frequent, indicating the potential importance of $\mathrm{BC}$ in water cycle over the tropics. An exponential relationship between precipitation and SST over the Niño-3.4 region is also evident (Figs. 4c,d; note the logarithmic scale in the ordinate), in agreement with the similar relationship found in 21 CMIP5 coupled global climate models (Cai et al. 2015). Using monthly ENSO indices leads to qualitatively similar conclusions.

\section{Potential mechanisms of $\mathrm{BC}$ impacts on extreme ENSO frequency}

Some previous studies found that increases in mean temperature could increase ENSO amplitudes and the frequency of extreme ENSO events (Cai et al. 2014, 2015; Wang et al. 2019). To understand the potential impacts of BC emissions on ENSO, it is necessary to examine changes in energy balance and mean SST between the perturbed and PD simulations. Unlike the global uniform distribution of well-mixed greenhouse gases (GHGs), BC is mainly distributed near its source regions. Increases in $\mathrm{BC}$ emissions in MID7X and ARC150X substantially increase BC burden in the mid- and high latitudes of the Northern Hemisphere, but have much less impact on BC burdens over the tropics (Figs. 5a,b). The additional BC transported from the mid- and high latitudes results in a direct TOA forcing of 0.59 and $0.03 \mathrm{~W} \mathrm{~m}^{-2}$ over the tropical oceans $\left(20^{\circ} \mathrm{S}-20^{\circ} \mathrm{N}\right)$ through solar absorption (Figs. 5c,d). However, combining all the $\mathrm{BC}$ aerosol-radiation and aerosol-cloud interactions, as well as the fast and slow feedback processes in the climate system, increases in $\mathrm{BC}$ emissions actually induce a net TOA cooling effect 


\section{a}

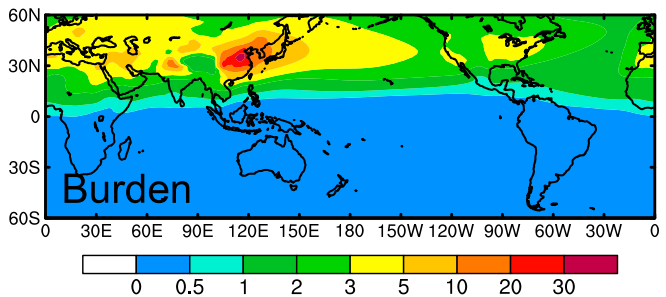

C

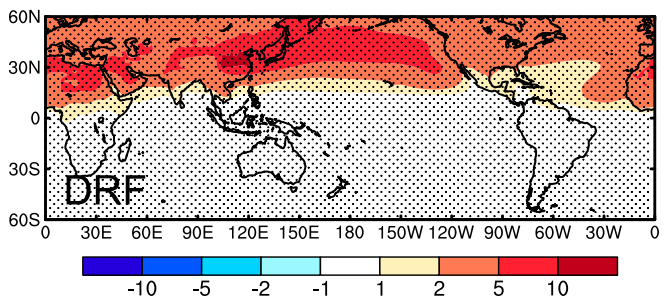

e

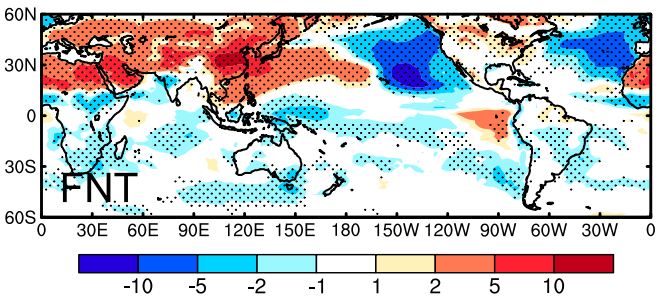

b ARC150X-PD

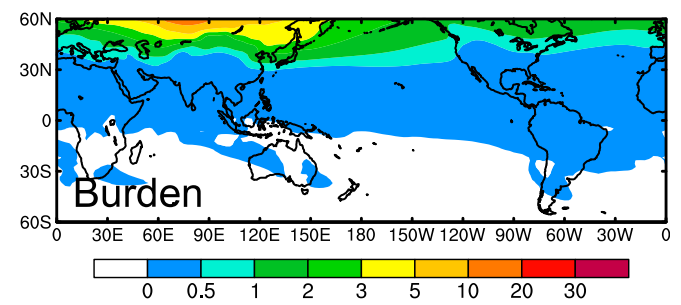

d

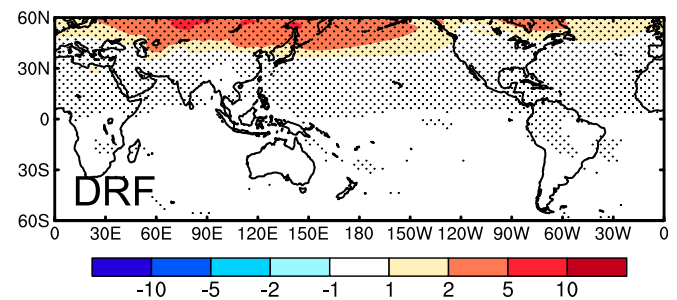

f

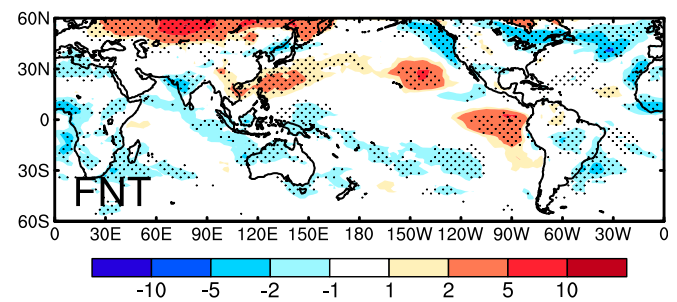

FIG. 5. Changes in annual mean (a),(b) BC column burden $\left(\mathrm{mg} \mathrm{m}^{-2}\right),(\mathrm{c}),(\mathrm{d})$ direct radiative forcing (DRF; $\mathrm{W} \mathrm{m}^{-2}$ ), and (e),(f) net radiative flux at TOA (FNT; $\mathrm{W} \mathrm{m}^{-2}$ ) in (left) MID7X and (right) ARC150X relative to PD,

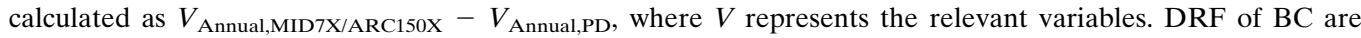
calculated in each simulation as the difference in net radiative flux at TOA with and without BC included in the radiative transfer calculation. The stippled areas indicate statistical significance with $95 \%$ confidence level from a Wilcoxon rank-sum test.

of -0.51 and $-0.20 \mathrm{~W} \mathrm{~m}^{-2}$ over the tropical oceans for MID7X and ARC150X (Figs. 5e,f), respectively.

Through absorbing solar radiation, $\mathrm{BC}$ warms most of the oceans between $30^{\circ}$ and $60^{\circ} \mathrm{N}$ in the Northern Hemisphere where its emissions are perturbed (Fig. 6). The enhanced BC heating in the Northern Hemisphere then weakens the latitudinal temperature gradient between the tropics and the higher latitudes. The weakened temperature gradient further reduces northward heat transport from the tropics in both atmosphere and oceans in MID7X and ARC150X (Fig. 7), a response also noted in Sand et al. (2013). The changes in northward heat transport in the atmosphere are due to the change in meridional circulation caused by $\mathrm{BC}$ forcing. An interhemispheric asymmetric adjustment in the surface temperature caused by aerosol forcing can induce an anomalous Hadley circulation over the tropics (Broccoli et al. 2006; Ocko et al. 2014), thereby causing the change in northward atmospheric heat transport.
The dynamical ocean response plays a dominant role in connecting the effects of Arctic sea ice loss to the entire globe through reducing northward oceanic heat transport (Tomas et al. 2016).

Changes in the meridional heat transport in both the atmosphere and the ocean can lead to energy convergence or divergence in the tropics, with important climatic consequence in the tropical ocean. The BC forcing in MID7X gives rise to a net energy convergence (reduced energy divergence) of $0.10 \mathrm{PW}$ in the tropical atmosphere $\left(20^{\circ} \mathrm{S}-20^{\circ} \mathrm{N}\right)$, but almost zero net energy change in the ocean. While the high-latitude emission in ARC150X can produce a net energy convergence (reduced energy divergence) in both tropical ocean (magnitude $=0.07 \mathrm{PW}$ ) and tropical atmosphere (magnitude $=0.02 \mathrm{PW})($ Table 2 and Fig. 7).

The mean-state tropical SST response to global warming is under debate (Tokinaga et al. 2012; Kohyama et al. 2017; Liu et al. 2018; Seager et al. 2019). In this study, 


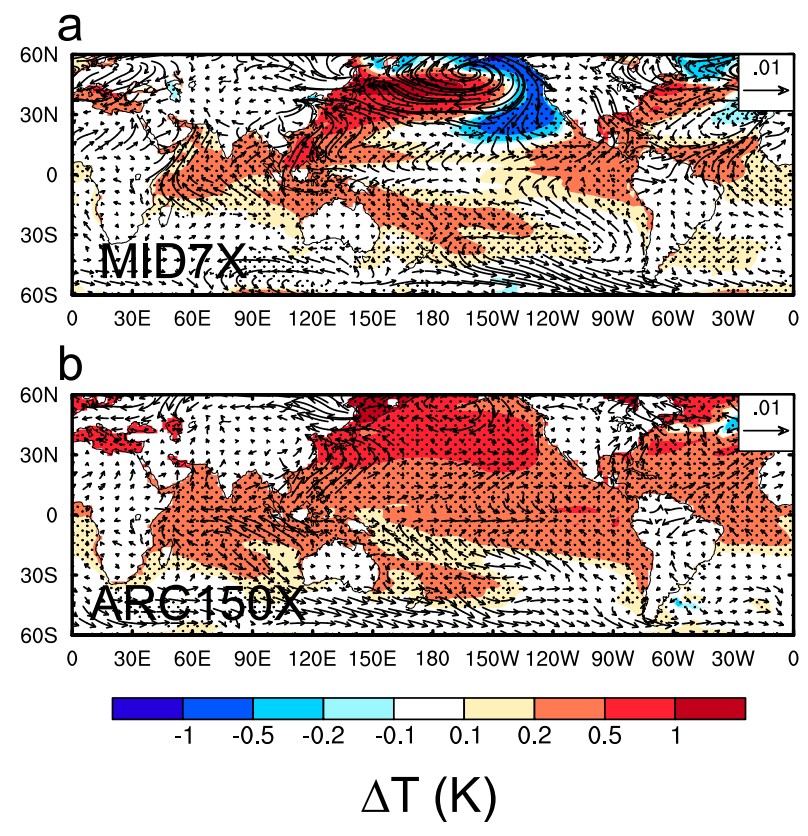

FIG. 6. Changes in annual mean SST (contours; K) and surface wind stress $\left(\mathrm{N} \mathrm{m}^{-2}\right)$ in (a) MID7X and (b) ARC150X relative to $\mathrm{PD}$, calculated as $V_{\text {Annual,MID7X/ARC150X }}-V_{\text {Annual,PD. }}$

the large contribution of the ocean heat transport to the tropical SST warming in experiment ARC150X points to the importance of the oceanic pathway in the tropical ocean response to high-latitude forcing (Deser et al. 2015; Tomas et al. 2016). Notably, both the SST response (Fig. 6a) and the vertical ocean temperature stratification in the eastern equatorial Pacific (Fig. 8) in the ARC150X experiment show considerable resemblance to those in response to the melting of Arctic sea ice reported in Tomas et al. (2016, their Figs. 5 and 6), in which the subsurface warming (below $100 \mathrm{~m}$ ), being advected by the mean upwelling, sustains the warming anomaly in the eastern equatorial Pacific, although the mechanisms responsible for the subsurface warming remain to be understood. As such, it is likely that the same mechanism as Tomas et al. (2016) is operating here for the warming in the tropical Pacific despite the very different source of forcing. However, the SST response pattern in MID7X (Fig. 6b) shows less organized warming in the tropics as compared to ARC150X.

The connection between changes in mean state of the tropical ocean and the extreme phases of the ENSO can be complicated. Given the likely oceanic pathway for the $\mathrm{BC}$ forcing to influence the ENSO amplitude, we can only speculate as to the possible mechanism based on the changes in the mean ocean stratification structure in the tropical Pacific (Fig. 8). Very similar features to Fig. 8 are also found in an experiment with CESM under an uniform heat input into the global ocean (no forcing is applied to the land grid points) in Wang et al. (2019), wherein careful heat budget analysis and Bjerknes linear stability index analysis were performed to relate the change of ENSO amplitude to the change in the mean state. According to this study, the increased stratification and the shoaling of the thermocline in the central and eastern Pacific tend to sustain a stronger thermocline feedback (also noted by Liu et al. 2011). Due to the

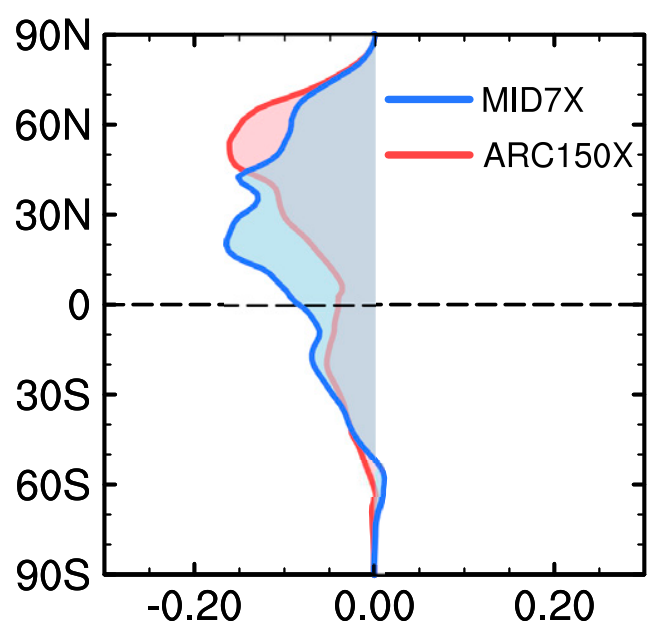

$\Delta$ NHT-Atmos. (PW)

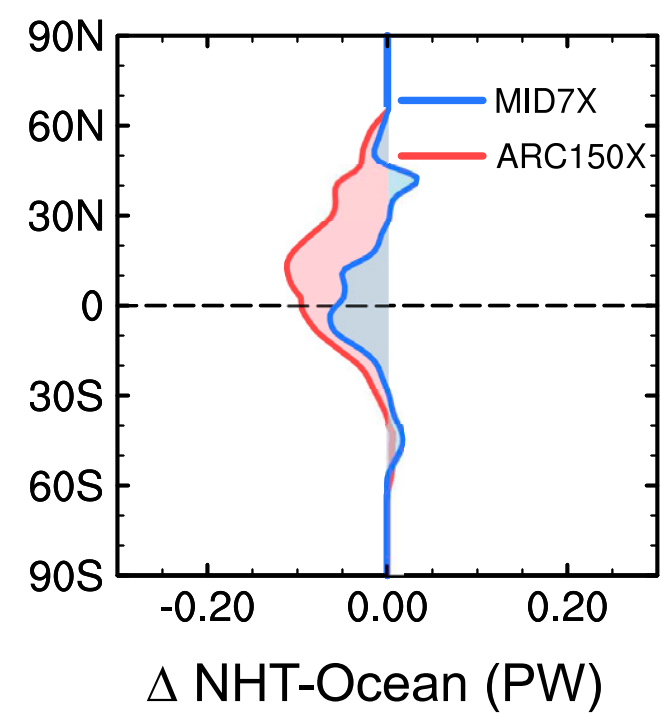

FIG. 7. Zonal mean changes in annual northward heat transport (NHT) in the (left) atmosphere and (right) oceans in MID7X (blue) and ARC150X (red) relative to PD, as calculated by $V_{\text {Annual,MID7X/ARC150X }}-V_{\text {Annual,PD }}$. NHT in the atmosphere is calculated as the residual of the TOA and surface energy budget. NHT in the oceans is calculated as the opposite number of net downward energy over ocean surface. 
TABLE 2. Annual NHT (PW) in the atmosphere and oceans in MID7X and ARC150X relative to PD at $20^{\circ} \mathrm{S}$ and $20^{\circ} \mathrm{N}$, as well as energy changes $(\mathrm{PW})$ over the tropical ocean $\left(20^{\circ} \mathrm{S}-20^{\circ} \mathrm{N}\right)$.

\begin{tabular}{|c|c|c|c|c|c|c|}
\hline \multirow[b]{2}{*}{ Simulation } & \multicolumn{2}{|c|}{$\Delta \mathrm{NHT}$ at $20^{\circ} \mathrm{N}$} & \multicolumn{2}{|c|}{$\Delta \mathrm{NHT}$ at $20^{\circ} \mathrm{S}$} & \multicolumn{2}{|c|}{$\Delta$ Energy over $20^{\circ} \mathrm{S}-20^{\circ} \mathrm{N}$} \\
\hline & Atmosphere & Ocean & Atmosphere & Ocean & Atmosphere & Ocean \\
\hline MID7X & -0.164 & -0.012 & -0.068 & -0.012 & +0.096 & 0.000 \\
\hline ARC150X & -0.070 & -0.098 & -0.054 & -0.031 & +0.016 & +0.067 \\
\hline
\end{tabular}

stratification change, the same wind stress anomalies can drive much stronger zonal current and wave response in the upper ocean, enhancing the zonal advection feedback (Li et al. 2016) during the development of ENSO. As the thermocline and zonal advection feedbacks are the leading major positive feedbacks during the development of ENSO extreme events in this model, the enhancement of these two feedbacks should lead to more frequent extremes for both cold and warm phases. We conjecture that the same mechanisms are likely operating to increase the frequency of extreme El Niño and La Niña events under the BC forcing. Meanwhile, as noted by Cai et al. (2015), the discharged state after a major El Niño event is more inducive to a La Niña event. Thus, the increased frequency of extreme El Niño may spawn a more favorable condition for extreme La Niña. Notwithstanding, Cai et al. (2015) further argued that the faster warming in Maritime Continent compared to the surrounding oceans acts to suppress the convection over the central equatorial Pacific, together with the increased thermal stratification, making it easier to trigger Bjerknes feedback, a factor absent during the development of extreme El Niño events. Without careful analysis and hypothesis-driven experiments, we refrain from addressing the nuanced asymmetry between the two opposite extreme phases of ENSO, a topic left for future investigation.

\section{Conclusions}

The impact of increases in midlatitude and Arctic $\mathrm{BC}$ emissions on the frequency of extreme ENSO events is examined in this study based on a set of fully coupled simulations using a global aerosol-climate model (CESM). Increases in $\mathrm{BC}$ emissions from the Northern Hemisphere midlatitudes and Arctic increases atmospheric BC substantially and warms the atmosphere and oceans in the Northern Hemisphere, leading to a weakened latitudinal temperature gradient. The weakened temperature gradient further reduces northward heat transport from the tropics and reduces tropical energy divergence in the atmosphere for the midlatitude $\mathrm{BC}$ perturbation and in both the atmosphere and ocean for the Arctic perturbation, leading to an increase of SST in the tropical Pacific, which in turn gives rise to more frequent extreme El Niño and La Niña events.

In this study, we found that $\mathrm{BC}$ emissions from midlatitudes and the Arctic can increase the frequency of extreme ENSO events in a climate system represented by CESM. However, it is difficult to extrapolate this finding to the real world, as how the ENSO variability responds to external climate forcings remains a topic of debate due to the fact that ENSO is controlled by a delicate balance of a plethora of amplifying and damping feedbacks (Collins et al. 2010). Therefore, we cannot rule out the possibility of model dependence with regard to this response, in view of the fact that some models
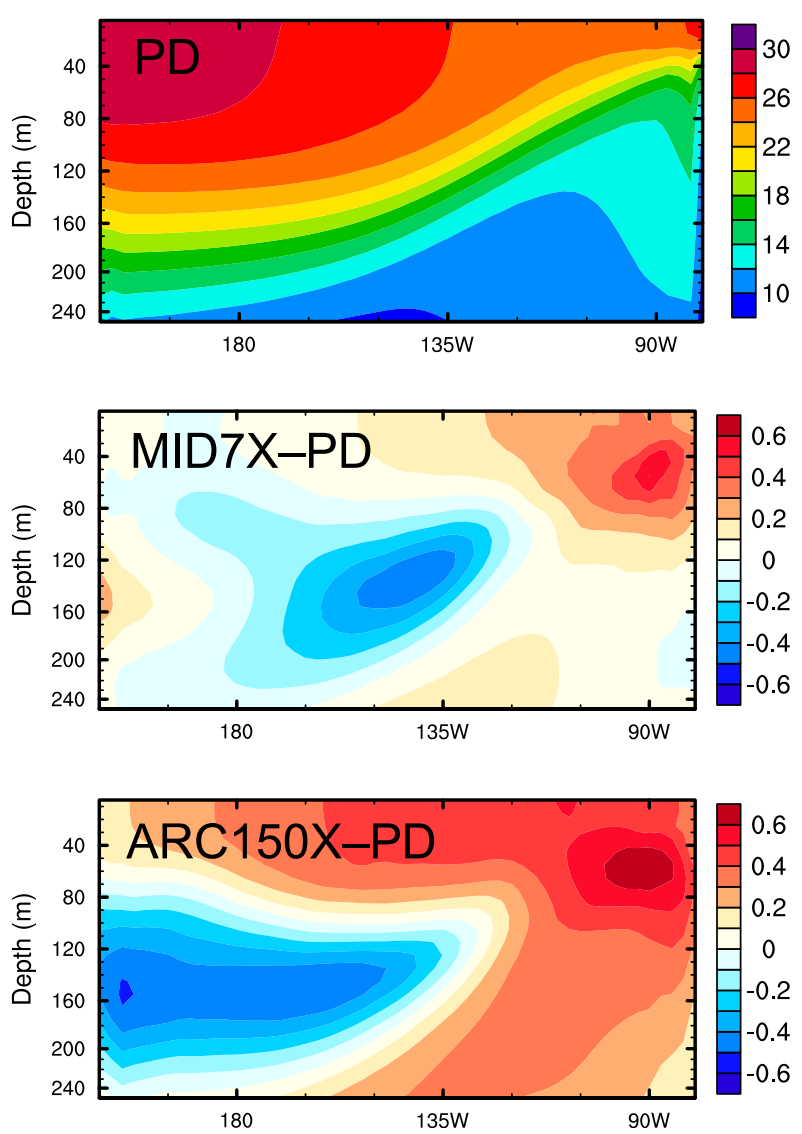

FIG. 8. Annual mean ocean temperature $\left({ }^{\circ} \mathrm{C}\right)$ at the equator $\left(5^{\circ} \mathrm{S}-\right.$ $5^{\circ} \mathrm{N}$ ) in (top) $\mathrm{PD}$ and changes in annual mean ocean temperature at the equator in (middle) MID7X and (bottom) ARC150X relative to PD. 
(e.g., GFDL-ESM2M) tend to simulate a weakened ENSO variability under global warming (Kohyama et al. 2018), while CESM shows the opposite tendency (Wang et al. 2019). The issue of model dependence warrants further investigation. In addition, the detailed model response to BC forcing was explored by scaling up BC emissions following Sand et al. (2013) to boost the signalto-noise ratio. To quantitatively investigate the ENSO response to $\mathrm{BC}$, the nonlinearity of the climate response to $\mathrm{BC}$ emissions also needs to be considered (Yang et al. 2019). So far, this study has been focusing on ENSO response to increases in BC emissions from the extratropics. It would be interesting to investigate how ENSO frequency and amplitude would respond to the changes in $\mathrm{BC}$ emission from the tropics, since ENSO can strongly perturb wildfire emissions in the tropical forests, possible feedbacks between ENSO and BC emission may exist.

Acknowledgments. This research was support by the National Natural Science Foundation of China under Grant 41975159, the U.S. Department of Energy (DOE), Office of Science, Biological and Environmental Research as part of the Earth and Environmental System Modeling program, the Jiangsu Specially Appointed Professor Project, and the NUIST Grant 2019r047. The Pacific Northwest National Laboratory is operated for DOE by Battelle Memorial Institute under Contract DE-AC05-76RLO1830. The National Energy Research Scientific Computing Center (NERSC) provided computational support. Model results are available through NERSC upon request. The authors acknowledge Dr. Lantao Sun for his very helpful input regarding the ocean dynamical mechanisms for the intensification of ENSO.

\section{REFERENCES}

AMAP, 2015: AMAP Assessment 2015: Black carbon and ozone as Arctic climate forcers. Arctic Monitoring and Assessment Programme, Oslo, Norway, vii +116 pp.

Baker, L. H., W. J. Collins, D. J. L. Olivié, R. Cherian, Ø. Hodnebrog, G. Myhre, and J. Quaas, 2015: Climate responses to anthropogenic emissions of short-lived climate pollutants. Atmos. Chem. Phys., 15, 8201-8216, https://doi.org/10.5194/ acp-15-8201-2015.

Boucher, O., and Coauthors, 2013: Clouds and aerosols. Climate Change 2013: The Physical Science Basis, T. F. Stocker et al., Eds., Cambridge University Press, 571-658, https://doi.org/ 10.1017/CBO9781107415324.016.

Bove, M. C., J. J. O'Brien, J. B. Eisner, C. W. Landsea, and X. E. Niu, 1998: Effect of El Niño on U.S. landfalling hurricanes, revisited. Bull. Amer. Meteor. Soc., 79, 2477-2482, https://doi.org/10.1175/ 1520-0477(1998)079<2477:EOENOO>2.0.CO;2.

Broccoli, A. J., K. A. Dahl, and R. J. Stouffer, 2006: Response of the ITCZ to Northern Hemisphere cooling. Geophys. Res. Lett., 33, L01702, https://doi.org/10.1029/2005GL024546.
Cai, W., and Coauthors, 2014: Increasing frequency of extreme El Niño events due to greenhouse warming. Nat. Climate Change, 4, 111-116, https://doi.org/10.1038/nclimate2100.

_ , and Coauthors, 2015: Increased frequency of extreme La Niña events under greenhouse warming. Nat. Climate Change, 5, 132-137, https://doi.org/10.1038/nclimate2492.

Collins, M., and Coauthors, 2010: The impact of global warming on the tropical Pacific and El Niño. Nat. Geosci., 3, 391-397, https://doi.org/10.1038/ngeo868.

Deser, C., R. A. Tomas, and L. Sun, 2015: The role of oceanatmosphere coupling in the zonal-mean atmospheric response to Arctic sea ice loss. J. Climate, 28, 2168-2186, https://doi.org/ 10.1175/JCLI-D-14-00325.1.

Flanner, M. G., C. S. Zender, J. T. Randerson, and P. J. Rasch, 2007: Present day climate forcing and response from black carbon in snow. J. Geophys. Res., 112, D11202, https://doi.org/ 10.1029/2006JD008003.

Golaz, J.-C., and Coauthors, 2019: The DOE E3SM coupled model version 1: Overview and evaluation at standard resolution. J. Adv. Model. Earth Syst., 11, 2089-2129, https://doi.org/ 10.1029/2018MS001603.

He, C., Q. Li, K.-N. Liou, Y. Takano, Y. Gu, L. Qi, Y. Mao, and L. R. Leung, 2014: Black carbon radiative forcing over the Tibetan Plateau. Geophys. Res. Lett., 41, 7806-7813, https:// doi.org/10.1002/2014GL062191.

Hoesly, R. M., and Coauthors, 2018: Historical (1750-2014) anthropogenic emissions of reactive gases and aerosols from the Community Emissions Data System (CEDS). Geosci. Model Dev., 11, 369-408, https://doi.org/10.5194/gmd-11-369-2018.

Hurrell, J. W., and Coauthors, 2013: The Community Earth System Model: A framework for collaborative research. Bull. Amer. Meteor. Soc., 94, 1339-1360, https://doi.org/10.1175/BAMS-D12-00121.1.

Jacobson, M. Z., 2006: Effects of externally-through-internallymixed soot inclusions within clouds and precipitation on global climate. J. Phys. Chem., 110A, 6860-6873, https:// doi.org/10.1021/jp056391r.

Kay, J. E., and Coauthors, 2015: The Community Earth System Model (CESM) Large Ensemble Project: A community resource for studying climate change in the presence of internal climate variability. Bull. Amer. Meteor. Soc., 96, 1333-1349, https://doi.org/10.1175/BAMS-D-13-00255.1.

Kohyama, T., D. L. Hartmann, and D. S. Battisti, 2017: La Niñalike mean-state response to global warming and potential oceanic roles. J. Climate, 30, 4207-4225, https://doi.org/10.1175/ JCLI-D-16-0441.1.

,-- , and,- 2018 : Weakening of nonlinear ENSO under global warming. Geophys. Res. Lett., 45, 8557-8567, https:// doi.org/10.1029/2018GL079085.

Li, G., S.-P. Xie, Y. Du, and Y. Luo, 2016: Effects of excessive equatorial cold tongue bias on the projections of tropical $\mathrm{Pa}$ cific climate change. Part I: The warming pattern in CMIP5 multi-model ensemble. Climate Dyn., 47, 3817-3831, https:// doi.org/10.1007/s00382-016-3043-5.

Liu, F., J. Lu, O. Garuba, L. R. Leung, Y. Luo, and X. Wan, 2018: Sensitivity of surface temperature to oceanic forcing via $q$-flux Green's function experiments. Part I: Linear response function. J. Climate, 31, 3625-3641, https://doi.org/10.1175/JCLID-17-0462.1.

Liu, L., W. Yu, and T. Li, 2011: Dynamic and thermodynamic air-sea coupling associated with the Indian Ocean dipole diagnosed from 23 WCRP CMIP3 models. J. Climate, 24, 4941-4958, https://doi.org/10.1175/2011JCLI4041.1. 
Liu, X., P.-L. Ma, H. Wang, S. Tilmes, B. Singh, R. C. Easter, S. J. Ghan, and P. J. Rasch, 2016: Description and evaluation of a new four-mode version of the Modal Aerosol Module (MAM4) within version 5.3 of the Community Atmosphere Model. Geosci. Model Dev., 9, 505-522, https://doi.org/10.5194/gmd-9505-2016.

Lou, S., Y. Yang, H. Wang, S. J. Smith, Y. Qian, and P. J. Rasch, 2019: Black carbon amplifies haze over the North China Plain by weakening the East Asian winter monsoon. Geophys. Res. Lett., 46, 452-460, https://doi.org/10.1029/2018GL080941.

Maher, N., S. McGregor, M. H. England, and A. S. Gupta, 2015: Effects of volcanism on tropical variability. Geophys. Res. Lett., 42, 6024-6033, https://doi.org/10.1002/2015GL064751.

Massey, F. J., 1951: The Kolmogorov-Smirnov test for goodness of fit. J. Amer. Stat. Assoc., 46, 68-78, https://doi.org/10.1080/ 01621459.1951 .10500769$.

McGregor, S., and A. Timmermann, 2011: The effect of explosive tropical volcanism on ENSO. J. Climate, 24, 2178-2191, https://doi.org/10.1175/2010JCLI3990.1.

McPhaden, M. J., S. E. Zebiak, and M. H. Glantz, 2006: ENSO as an integrating concept in Earth science. Science, 314, 1740 1745, https://doi.org/10.1126/science.1132588.

Ocko, I. B., V. Ramaswamy, and Y. Ming, 2014: Contrasting climate responses to the scattering and absorbing features of anthropogenic aerosol forcings. J. Climate, 27, 5329-5345, https://doi.org/10.1175/JCLI-D-13-00401.1.

Ohba, M., H. Shiogama, T. Yokohata, and M. Watanabe, 2013: Impact of strong tropical volcanic eruptions on ENSO simulated in a coupled GCM. J. Climate, 26, 5169-5182, https:// doi.org/10.1175/JCLI-D-12-00471.1.

Otto-Bliesner, B. L., and Coauthors, 2016: Climate variability and change since $850 \mathrm{CE}$ : An ensemble approach with the Community Earth System Model. Bull. Amer. Meteor. Soc., 97, 735-754, https://doi.org/10.1175/BAMS-D-14-00233.1.

Qian, Y., and Coauthors, 2015: Light-absorbing particles in snow and ice: Measurement and modeling of climatic and hydrological impact. Adv. Atmos. Sci., 32, 64-91, https://doi.org/ 10.1007/s00376-014-0010-0.

Ramanathan, V., and G. Carmichael, 2008: Global and regional climate changes due to black carbon. Nat. Geosci., 1, 221-227, https://doi.org/10.1038/ngeo156.

Ropelewski, C. F., and M. S. Halpert, 1987: Global and regional scale precipitation patterns associated with the El Niño/ Southern Oscillation. Mon. Wea. Rev., 115, 1606-1626, https:// doi.org/10.1175/1520-0493(1987)115<1606:GARSPP>2.0.CO;2.

Rotstayn, L. D., M. A. Collier, R. M. Mitchell, Y. Qin, S. K. Campbell, and S. M. Dravitzki, 2011: Simulated enhancement of ENSOrelated rainfall variability due to Australian dust. Atmos. Chem. Phys., 11, 6575-6592, https://doi.org/10.5194/acp-11-6575-2011.

Sand, M., T. K. Berntsen, Ø. Seland, and J. E. Kristjánsson, 2013: Arctic surface temperature change to emissions of black carbon within Arctic or midlatitudes. J. Geophys. Res., 118, 77887798, https://doi.org/10.1002/jgrd.50613.

_ , T. Iversen, P. Bohlinger, A. Kirkevåg, I. Seierstad, Ø. Seland, and A. Sorteberg, 2015: A standardized global climate model study showing unique properties for the climate response to black carbon aerosols. J. Climate, 28, 2512-2526, https:// doi.org/10.1175/JCLI-D-14-00050.1.

Seager, R., M. Cane, N. Henderson, D. E. Lee, R. Abernathey, and H. Zhang, 2019: Strengthening tropical Pacific zonal sea surface temperature gradient consistent with rising greenhouse gases. Nat. Climate Change, 9, 517-522, https://doi.org/10.1038/ s41558-019-0505-x.
Stevenson, S., B. Otto-Bliesner, J. Fasullo, and E. Brady, 2016: "El Niño like" hydroclimate responses to last millennium volcanic eruptions. J. Climate, 29, 2907-2921, https://doi.org/10.1175/JCLI-D-15-0239.1.

Stjern, C. W., and Coauthors, 2017: Rapid adjustments cause weak surface temperature response to increased black carbon concentrations. J. Geophys. Res., 122, 11462-11481, https:// doi.org/10.1002/2017JD027326.

Tang, T., and Coauthors, 2018: Dynamical response of Mediterranean precipitation to greenhouse gases and aerosols. Atmos. Chem. Phys., 18, 8439-8452, https://doi.org/10.5194/acp-188439-2018.

Tokinaga, H., S.-P. Xie, C. Deser, Y. Kosaka, and Y. M. Okumura, 2012: Slowdown of the Walker circulation driven by tropical Indo-Pacific warming. Nature, 491, 439-443, https://doi.org/ 10.1038/nature11576.

Tomas, R. A., C. Deser, and L. Sun, 2016: The role of ocean heat transport in the global climate response to projected Arctic sea ice loss. J. Climate, 29, 6841-6859, https://doi.org/10.1175/ JCLI-D-15-0651.1.

Wang, H., and Coauthors, 2013: Sensitivity of remote aerosol distributions to representation of cloud-aerosol interactions in a global climate model. Geosci. Model Dev., 6, 765-782, https:// doi.org/10.5194/gmd-6-765-2013.

Wang, Y., Y. Luo, J. Lu, and F. Liu, 2019: Changes in ENSO amplitude under climate warming and cooling. Climate Dyn., 52, 1871-1882, https://doi.org/10.1007/s00382-018-4224-1.

$\mathrm{Xu}, \mathrm{L}$., and Coauthors, 2016: DMS role in ENSO cycle in the tropics. J. Geophys. Res., 121, 13 537-13 558, https://doi.org/ 10.1002/2016JD025333.

Xue, D., J. Lu, L. Sun, G. Chen, and Y. Zhang, 2017: Local increase of anticyclonic wave activity over northern Eurasia under amplified Arctic warming. Geophys. Res. Lett., 44, 3299-3308, https://doi.org/10.1002/2017GL072649.

Yang, Y., and Coauthors, 2016a: Impacts of ENSO events on cloud radiative effects in preindustrial conditions: Changes in cloud fraction and their dependence on interactive aerosol emissions and concentrations. J. Geophys. Res., 121, 6321-6335, https:// doi.org/10.1002/2015JD024503.

, L. M. Russell, S. Lou, M. A. Lamjiri, Y. Liu, B. Singh, and S. J. Ghan, 2016b: Changes in sea salt emissions enhance ENSO variability. J. Climate, 29, 8575-8588, https://doi.org/ 10.1175/JCLI-D-16-0237.1.

, H. Wang, S. J. Smith, P.-L. Ma, and P. J. Rasch, 2017a: Source attribution of black carbon and its direct radiative forcing in China. Atmos. Chem. Phys., 17, 4319-4336, https://doi.org/ 10.5194/acp-17-4319-2017.

— , and Coauthors, 2017b: Global source attribution of sulfate concentration and direct and indirect radiative forcing. Atmos. Chem. Phys., 17, 8903-8922, https://doi.org/10.5194/acp-17-89032017.

, H. Wang, S. J. Smith, R. Zhang, S. Lou, H. Yu, C. Li, and P. J. Rasch, 2018: Source apportionments of aerosols and their direct radiative forcing and long-term trends over continental United States. Earth's Future, 6, 793-808, https://doi.org/ 10.1029/2018EF000859.

, S. J. Smith, H. Wang, C. M. Mills, and P. J. Rasch, 2019: Variability and timescales in the climate response to black carbon emissions. Atmos. Chem. Phys., 19, 2405-2420, https:// doi.org/10.5194/acp-19-2405-2019.

Yu, X., Z. Wang, H. Zhang, and S. Zhao, 2019: Impacts of different types and intensities of El Niño events on winter aerosols over China. Sci. Total Environ., 655, 766-780, https://doi.org/10.1016/ j.scitotenv.2018.11.090. 